\title{
Bilecik Yöresi Mermer Atıklarının "Fiber-Sement" Üretiminde Kullanılabilirliğinin Araştırılması
}

\author{
Ali Murat SOYDAN ${ }^{1}$, Abdulkadir SARI ${ }^{2}$, Recep AKDENIZ ${ }^{2}$
}

ÖZET: Bu çalışmada, Bilecik bölgesinde bulunan mermer yataklarındaki mermer blokların kesilip, işlenmesi sonucu oluşan atık mermer tozlarının elyaf takviyeli çimento matrisli kompozit (Fiber-Sement; FS) levhaların üretiminde kullanılabilirliği araştırılmıştır. FS levhaların üretimi için ana hammadde olarak çimento, silis kumu, atık mermer tozu ve selüloz kullanılmıştı. Bu hammaddelerin sırasıyla kimyasal bileșimi ve tane boyutu gibi kimyasal ve fiziksel özellikleri ve FS üzerine etkileri araştırılmıştır. Mermer atığı kütlece \%0-50 oranlarında eklenmiştir ve FS levhalarının mekaniksel özelliklerine etkileri araştırılmıştır. Üretilen numuneler üzerinde yapılan fiziksel ve mekaniksel test sonuçlarına göre atık mermer tozları kullanılarak kendi grubunda yeterli mekanik özellikleri sağlayan ve daha ekonomik olan elyaf takviyeli çimento matrisli kompozit FS panellerin üretilebileceği belirlenmiştir.

Anahtar Kelimeler: Fiber-sement, atık mermer tozu, elyaf takviyeli çimento kompozit.

\section{Investigation of the Usability of Bilecik Region's Waste Marble Powders in "Fiber-Cement" Production}

\begin{abstract}
In this study, it was investigated the usability of waste marble powders obtained from cutting and processing of marble blocks in marble ores in Bilecik region in the production of fiber reinforced cement matrix composite (Fiber-Cement; FC) sheets. Cement, silica sand, waste marble powder, and cellulose were used as main raw materials for the production of FC sheets. The chemical and physical properties of these raw materials such as chemical composition and grain size, respectively, and their effects on FC were investigated. The marble waste was added to the wt. $0-50 \%$ and the effects of mechanical properties of FC sheets were investigated. According to the physical and mechanical test results on the produced samples; it was determined that the fiber reinforced cement matrix composite (FC) sheets can be produced in their class with sufficient mechanical properties and more economically by using waste marble powder.
\end{abstract}

Keywords: Fiber-cement, waste marble powder, fiber reinforced cement composite.

Ali Murat SOYDAN (0000-0001-5660-1487), Gebze Teknik Üniversitesi, Enerji Teknolojileri Enstitüsü, Kocaeli/Gebze, Türkiye

Abdulkadir SARI (0000-0002-6471-717X), Recep AKDENIZ (0000-0002-8072-0862), Gebze Teknik Üniversitesi, Materyal Bilimi ve Mühendisliği, Bölümü, Kocaeli/Gebze, Türkiye

Sorumlu yazar/Corresponding Author: Ali Murat SOYDAN, asoydan@gtu.edu.tr 


\section{GİRiș}

Uzun yıllardır inşaat malzemesi olarak kullanılan ve Fiber-Sement (FS) olarak adlandırılan elyaf takviyeli ve çimento matrisli kompozit levhalar, çeşitli organik veya mineral fiberlerin çimento ile belirli oranlarda karıştırılması ile düz veya oluklu şekilde üretilirler. FS levhalar, genellikle dış cephe kaplaması olarak kullanılmasının yanı sıra iç duvar ve zemin malzemesi olarak da kullanılmaktadır (Khorami and Ganjian, 2011). FS levhaların üretiminde agrega olarak genellikle aktif silis kumu kullanılmaktadır. Üretimde kullanılan malzemenin belirli bir kısmının veya tamamının atık malzemelerle değiştirilmesi üzerine çeşitli çalışmalar yapılmıştır (Ünal ve Kibici, 2001). İnşaat sektörü, tek başına hem dünyadaki enerji tüketiminin \%30-40’lık kısmına sahip hem de hammaddelerin bol miktarda kullanıldığı ve dolayısıyla oldukça fazla atığın ortaya çıktığı bir alandır. Bu sebeple, atıkların geri dönüşümünü sağlama, temel hammadde tüketiminin ve aynı zamanda enerji sarfiyatının azaltılabileceği en önemli alanlardan biri inşaat sektörüdür (Kacir, 2017).

Türkiye toplam 5.2 milyar $\mathrm{m}^{3}$ 'lük (13.9 milyar ton) mermer rezervi ile dünya rezervinin yaklaşık \%40'ina sahip, mermer açısından dünyanın zengin ülkeleri arasında yer almaktadır (Çetin, 2003). Mermer atıkları, ya ocaklarda blok mermer üretimi sürecinde veya mermerlerin kullanılabilmesi için blokların fabrikada kesilerek işlenmesi ya da plaka mermer üretimi esnasında oluşur (Yıldız ve Eskikaya, 1995; Kara ve Yazicioglu, 2016). Türkiye'de, yıllık olarak üretilen 7 milyon ton mermerden açığa çıkan ve milyon tonla ifade edilebilecek \%40-60 oranındaki kısmı atık olarak yol kenarlarına veya üretim tesislerinin etrafina dökülmektedir. Toz mermer atıkları çok ince boyutlarda olduğu için hava ve su kirliliğine neden olmaktadır. Mermer atığı tozların büyük çoğunluğu $\leq 250 \mu \mathrm{m}$ tane boyutuna sahiptir (Kara ve Yazicioglu, 2016; Talah et al., 2015). Bu atık tozların yüksek alkalin derecesine sahip olması kirlilik derecesi ile tarif edilebilir. Atık mermer çamurları geçici ve uzun süreli olarak tarım arazilerinin, toprak ve ekinlerin kirlenmesine neden olmaktadır (Ceylan ve Mança, 2013; Sutcu et al., 2015). Önemli bir çevre problemi olan mermer atıkları, her yıl yaklaşık olarak dünyada 5-6 milyon ton Türkiye'de ise 2.5 milyon ton olarak ortaya çıkmaktadır. $\mathrm{Bu}$ atıkların değerlendirilmesi üzerine yapılmış birçok araştırma olmasına rağmen maalesef atıklar düzgün bir şekilde bertaraf edilememekte veya geri dönüştürülememektedir (Alyamac et al., 2017; Singh et al., 2017). Mermer atıklarının değerlendirilebilmesi için önemli bir alternatif, inşaat sektöründe kullanılmasıdır. Böylece atıklar hem ekonomiye kazandırılabilir hem de doğaya ve çevreye olan zararları en aza indirilebilir (Kacir, 2017; Ceylan ve Mança, 2013; Sutcu et al., 2015).

Mermer atıklarının değerlendirilmesi ile ilgili çok sayıda araştırma yapılmıştır (Ceylan ve Mança, 2013). Yıldız ve Eskikaya (1995), Afyon yöresi mermer tozu atıklarının katk1 veya dolgu malzemesi olarak saf kalsit yerine veya ikame ederek kullanılabileceği alanları araştırmışlardır. Mermer tozu atıkları farklı alanlarda kullanımının yanı sıra hava kirliliğinin önlenmesinde ve Fuga dolgu malzemesi üretiminde de kullanılabilmektedir (Ceylan ve ark., 2001). Diğer yandan atık mermer tozlarının beton üretiminde ve havuz çökeltisi olan mermer tozlarının yapı bloğu üretiminde kullanımı mümkün olabilmektedir (Ünal ve Kibici, 2001; Demir ve Başpınar, 2003). Mermer atıklarının beton içerisinde \%0100 arasındaki oranlarda agrega olarak kullanılmasının betonun mukavemetini artırdığ 1 tespit edilmiştir (Kore and Vyas, 2016). Yapılan araştırmaların sonuçlarına göre, betonların içerisinde mermer tozu kullanımı, betonların fiziksel ve mekanik özelliklerini yükseltmektedir (Filiz ve ark., 2010). Bilecik Mermer Sektörünün 2017 yılı raporunda, 2014-2023 yılları arası Bursa, Eskişehir ve Bilecik Bölge planında, ilçelerde sürdürülen madencilik faaliyetlerinden dolayı çevre kirliliğinin önüne geçmek için mermer atıklarının değerlendirilmesi, atıkların kırıldıktan sonra çakıl haline getirilerek kullanılması ve mermer çamurunun sanayide girdi olarak kullanılması hedeflenmiştir (Kacir, 2017). Mermer tozları çimento özelliklerine sahiptir ve tozların tane boyutları küçüldükçe bağlayıcılık özellikleri artmaktadır (Singh et al., 2015). Bu çalışmada, Türkiye'nin mermer rezervleri ve üretimi bakımından en zengin bölgelerinden biri olan Bilecik yöresinde ki çevre açısından çok büyük bir sorun olan mermer atıklarının Fiber-Sement üretiminde kullanılabilirliği araştırılmıştır. Altı farklı kompozisyonda her bir numune serisi için beşer tane numune hazırlayarak elde edilen ortalama değerlerle mermer atığı katk1 oranının ve diğer bileşenlerin üretilen FS'nin fiziksel ve mekaniksel özellikleri üzerine etkileri incelenmiştir.

\section{MATERYAL VE YÖNTEM}

\section{Hammaddeler}

Çimento: ÇiMSA'nın Eskişehir fabrikasından alınan klasik CEM I 42.5 R Portland Çimetosu kullanılmıştır. Elyaf: Cellulose Lerox International Şirketinden alınan Virgin Selüloz (VS) kırpılarak rafine edilmesi için pulp haline getirilmiştir ve mekanik mukavemete etkisini artırmak için 15 saat boyunca suda fibrilleşmesi sağlanmıştır. Silis Kumu: \%95'in üzerinde silis oranına sahip kum, Türkiye'nin silisçe zengin bölgesi olan Şile'de 
faaliyet gösteren Ergen Madencilikten temin edilmiştir. Mermer Attğı olarak: Bilecik bölgesinde çalışan Durmuş MermerFabrikasından temin edilen \%50'nin üzerinde $\mathrm{CaO}$ oranına sahip mermer tozları kullanılmıştır. Karışımları hazırlamak için geri dönüşüm suyu $(\mathrm{pH}=13)$ kullanılmıştır. Üretim hattında geri dönüşüm su kullanılmasının zorunlu olması sebebiyle laboratuvar çalışmalarında da geri kazanım suyu kullanılarak endüstriyel üretim koşulları birebir oluşturulmaya çalışılmıştır.

\section{Hammaddelerin Karakterizasyonu}

Elyaflar, çimento, silis kumu ve mermer atığının karakterizasyonu çeşitli test cihazları ve yöntemlerle yapılmıştır. Fiberlerin serbestlik derecesi Kanada Standart'1 (TAPPI, 1999) referans alınarak özel tasarım serbestlik cihazı ile ölçülmüsstür. Bütün hammaddelerin mikroyapı görüntüleri tarama elektron mikroskop (SEM) yardımıyla, tane boyutu ve boyut dağılımı lazer ışınları kırınımı yöntemiyle, kristal yapısı $\mathrm{X}$-1şınları Difraksiyonu (XRD) cihazıyla, kimyasal bileşimi ise $\mathrm{X}$-1şınları Flüoresans Analizi (XRF) ile incelenmiştir. Elyafların nem tayini yapıldıktan sonra serbestlik derecesi; ağaç hamurunun süspansiyon içindeki drenaj hızının ölçümü (1 L suda 3 gr kâğıt hamuru) olarak tanımlanmıştır. Bu analiz, elyafların sağlamlığına, ince parçacık içeriğine, morfolojisine, lif türüne, fibrilasyon derecesine ve elyaf esnekliğine bağlıdır (TAPPI, 1999). Ölçüm sonuçları; stok sıcaklığına, su kalitesine ve yüzey özelliklerine bağlıdır (ISO 5267-2:2001). Bu test Kanada Selüloz ve Kâğıt Araştırma Enstitüsü tarafindan geliştirilmiştir ve Kanada Standart Serbestliği olarak tanımlanır.

\section{Numune Hazırlama}

Üretimin ilk adımı, Fiber-Sement çamuru hazırlamaktır. FS çamuru, geri dönüșüm suyu, çimento, mermer atığ 1 ve silis kumundan oluşmuștur. Hammaddelerin karıșım oranları Çizelge 1'de verilmiştir. İlk önce 15 saat karıştırılmış olan selüloza sırasıly mermer atığı, çimento ve silis kumu olmak üzere eklenmiştir. Topaklaşmayı önlemek için ekleme işlemi yavaş olmalıdır. Çamurdaki çimento tanelerinin yapışmasını sağlamak için karışıma az miktarda flokülant eklenmiştir. Hazırlanan karışımın su/çimento oranı ağırlıkça \%30 olarak belirlenmiştir. Karıştırma sürecinde, karışım yaklaşık 820 ml'si 400 mbar'llk bir basınç seviyesinde suyu absorbe eden bir vakum kutusu içine konularak bulamaçtaki fazla su, vakum pompası ile emilir. Vakumlamadan sonra, numuneler presleme makinesine alınarak $7 \mathrm{MPa}$ 'lı bir basınç ile 120 saniye boyunca preslenmiştir. Böylece belirlenen her bir numune serisi için 5'er adet numune üretilmiştir. Numuneler, etüvde 6 saat boyunca $30^{\circ} \mathrm{C}^{\prime}$ de ön kürleme işlemine tabi tutulmuştur ve sonrasında sıcaklık gradyeni $60^{\circ} \mathrm{C} /$ saat olan otoklavda $180^{\circ} \mathrm{C}$ de 11 saat boyunca nihai olarak kürlenmiştir. Üretim akış şeması Şekil 1'de gösterilmektedir.

Çizelge 1. Hammaddelerin karışım oranları

\begin{tabular}{lcccc}
\hline & Çimento (\%) & Silis Kumu (\%) & Mermer atı̆̆ (\%) & Selüloz (\%) \\
\hline A0 & 24 & 68 & 0 & 8 \\
A1 & 24 & 58 & 10 & 8 \\
A2 & 24 & 48 & 20 & 8 \\
A3 & 24 & 38 & 30 & 8 \\
A4 & 24 & 28 & 40 & 8 \\
A5 & 24 & 18 & 50 & 8 \\
\hline
\end{tabular}

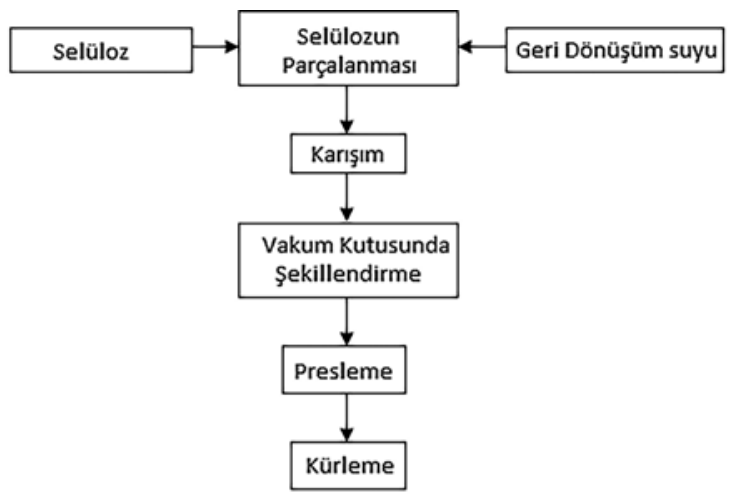

Şekil 1. FS kompozit malzeme üretiminin akış şeması. 


\section{Nihai Ürün Testleri ve Analizleri}

Üretilen ürünlerin mikro yapıları SEM ile incelenmiştir. Su emme, kütle yoğunluğu ve mekanik testleri TSE EN 12467 standardına göre yapılmıştır (TSE EN 12467, 2007). Kırılma Mukavemeti ve Elastik Modülü değerlerini belirlemek için numunelere $6 \mathrm{kN}$ 'luk üç nokta eğme testi cihazında (Yük-Deplasman) testleri yapılmıştır. Her bir test grubu için ayrı ayrı her numuneden $210 \mathrm{~mm} \times 76 \mathrm{~mm}$ ebatlarında 5'er adet üretilmiş, mesnetler arası $180 \mathrm{~mm}$ olan cihaza, numuneler sağ ve sol olmak üzere her iki kenarından 15'er mm dışarıda kalacak şekilde yerleştirilmiş ve cihaz yükleme hızı 10 $\mathrm{mm} / \mathrm{dk}$ olacak şekilde ayarlanarak test edilmiştir.

Kırılma işlemi 15 - 30 sn. aralığında gerçekleşmiştir. Bu çalışmada, Elastik Modülü ve Kırılma Mukavemeti için her 5 numunenin ortalama değerleri test sonucu olarak verilmiştir. $\mathrm{Bu}$ sonuçların hesaplanmasında üç nokta eğme testi konfigürasyonu kullanılmıştır (Jarabo et al., 2012);

$$
\begin{aligned}
& \text { Kırılma Mukavemeti }(\mathrm{MPa})=\left(\frac{\mathrm{L}_{\mathrm{Max}}}{\mathrm{b} \cdot \mathrm{h}^{2}}\right)-\left(\mathrm{S}_{\text {aşă̆ } 1}-\mathrm{S}_{\mathrm{yukar} 1}\right) \\
& \text { Elastik Modülü }(\mathrm{GPa})=\operatorname{tg} \alpha \cdot\left(\frac{\mathrm{L}_{\mathrm{Max}}}{\delta}\right) \cdot \frac{\left(\mathrm{S}_{\text {aşă̆ }}-\mathrm{S}_{\mathrm{yukar}}\right)^{3}}{\mathrm{~b} \cdot \mathrm{h}^{3}} \times 10^{6}
\end{aligned}
$$

Burada $\mathrm{L}_{\text {Max }}$ : maksimum yük, $\left(\mathrm{S}_{\text {aşăı̆ }}-\mathrm{S}_{\text {yukarr }}\right)$ : mesnetler arası mesafe $(\mathrm{mm})$, b: numune genişliği, $\mathrm{h}$ : numune kalınlığı, tg $\alpha$ : gerilme-gerinme eğrisinin başlangıç eğimi ve $\delta$ ise FS'deki yüke bağlı meydana gelen uzamadır (mm).

Üretilen numunelere, TSE 12467 kodlu standarda göre, Arşimet testi uygulanarak kütle yoğunluğu ve su emme değerleri ölçülmüştür. Örnekler, ağırlıkları sabit

$$
\begin{aligned}
& \text { Kütle Yoğunluğu }=\frac{\mathrm{w}_{1}}{\left(\mathrm{w}_{1}-\mathrm{w}_{2}\right)} \times 100 \\
& \text { Su Emme } \%=\frac{\left(\mathrm{w}_{3}-\mathrm{w}_{1}\right)}{\mathrm{w}_{1}} \times 100
\end{aligned}
$$

Burada, $\mathrm{W}_{1}$ firında kurutulduktan sonraki normal ağırlık, $\mathrm{W}_{2}$ su içindeki ağırlık, $\mathrm{W}_{3}$ ise suya doymuş haldeki normal ağırlıktır (Sudan çıkarılan numunenin yüzeyi nemli bir bezle silinerek havada tartılır).

\section{BULGULAR VE TARTIŞMA}

\section{Kullanılan Hammaddelerin Özellikleri}

Elyafların nem tayini ve Kanada Standartları referans alınarak yapılan serbestlik derecesi ölçüm işlemlerinden elde edilen Fiberlerin serbestlik derecesi hale gelene kadar etüvde kurutulmuştur $\left(\mathrm{W}_{1}\right)$. Ardından, numuneler 48 saat boyunca su içinde tutularak ve ağılıkları sabit hale gelene kadar beklendikten sonra Arşimet terazisi kullanılarak tartılmıştır $\left(\mathrm{W}_{2}\right)$. Numuneler doymuş ağırlıkları belirlemek için sudan çıkarılmıştır $\left(\mathrm{W}_{3}\right)$. Numunelerin yığın yoğunluğu ve su emme değerleri aşağıdaki denklemler kullanılarak belirlenmiştir; 
Çizelge 2. Fiberlerin fiziksel özellikleri

\begin{tabular}{ll}
\hline Özellik & Virgin Selüloz (VS) \\
\hline Ort. Çap $(\mu \mathrm{m}):$ & 29,7 \\
Serbestlik derecesi: & 32 \\
Kuruluk oranı \% & $80 \pm 2$ \\
Nem \% & 3,98 \\
\hline
\end{tabular}

FS üretiminde kullanılan silis kumu, çimento ve mermer atıklarının XRF kimyasal analiz sonuçları Çizelge 3'de, XRD sonuçları Şekil 2a'da ve tane boyut dağılımı Şekil 2b'de verilmiştir. En bariz olarak gözüken altıgen yapıya sahip kuvars pikidir (Rashid et al., 2014). Şekil 2b'de çimentonun ortalama tane boyutu (d50) $16.08 \mu \mathrm{m}$, mermer atığının ki (d50) $5.52 \mu \mathrm{m}$ ve 2 saat öğütme işlemine tabi tutulan silis kumunun ortalama tane boyutu (d50) $73.53 \mu \mathrm{m}$ olarak ölçülmüştür. BET yöntemi ile ölçülen çimentonun yüzey alanı $1.23 \mathrm{~m}^{2} \cdot \mathrm{g}^{-1}$, mermer atığının $2.17 \mathrm{~m}^{2} \cdot \mathrm{g}^{-1}$ ve silis kumununki ise $0.83 \mathrm{~m}^{2} \cdot \mathrm{g}^{-1}$ 'dir. Şekil 3'de FS üretimi için kullanılan hammaddelerin mikroyapısı gösterilmiş̧ir. Çimento ve mermer atığı hammadde granülleri homojen tanecik boyutuna sahip olmakla birlikte silis kumu farklı boyutlarda değişkenlik göstermektedir. Ancak, yüksek yoğunlukta bir yapı elde etmek açısından olumsuz bir durum değildir.

Çizelge 3. Hammaddelerin XRF kimyasal analizleri (\%)

\begin{tabular}{lllll}
\hline No. & Bileşen & Çimento & Mermer Atı̆̆ & Silis Kumu \\
\hline 1 & $\mathrm{Na}_{2} \mathrm{O}$ & 0.38 & - & - \\
2 & $\mathrm{MgO}$ & 1.88 & 1.69 & - \\
3 & $\mathrm{Al}_{2} \mathrm{O}_{3}$ & 4.74 & - & 0.93 \\
4 & $\mathrm{SiO}_{2}$ & 19.35 & 0.28 & 97.25 \\
5 & $\mathrm{P}_{2} \mathrm{O}_{5}$ & 0.08 & - & - \\
6 & $\mathrm{SO}_{3}$ & 2.72 & - & - \\
7 & $\mathrm{~K}_{2} \mathrm{O}$ & 0.53 & - & 0.31 \\
8 & $\mathrm{CaO}$ & 63.50 & 54.27 & 0.25 \\
9 & $\mathrm{TiO}_{2}$ & 0.36 & - & 0.26 \\
10 & $\mathrm{Cr}_{2} \mathrm{O}_{3}$ & 0.11 & - & - \\
11 & $\mathrm{MnO}_{12}$ & 0.08 & - & - \\
12 & $\mathrm{Fe}_{2} \mathrm{O}_{3}$ & 3.29 & 0.22 & 0.68 \\
13 & $\mathrm{LOI}$ & 3.01 & 43.55 & 0.34 \\
\hline
\end{tabular}

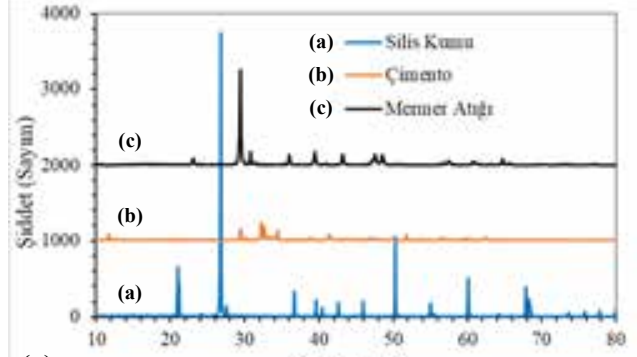

(a)

$2 \theta$ (Derese)

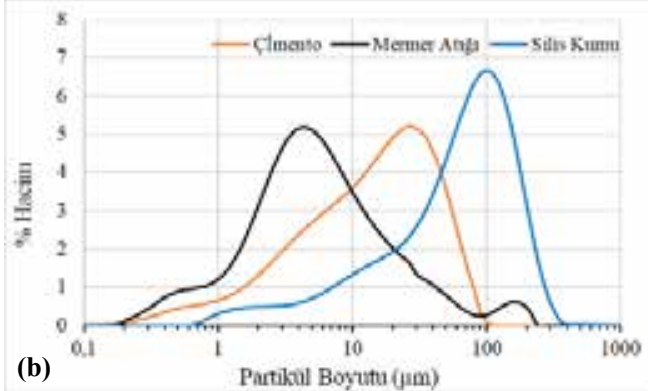

(b)

Şekil 2. Çimento, silis kumu ve mermer atığının XRD analizi (a), ve Çimen to, mermer atığı ve silis kumunun tane boyut dağılımı (b) 

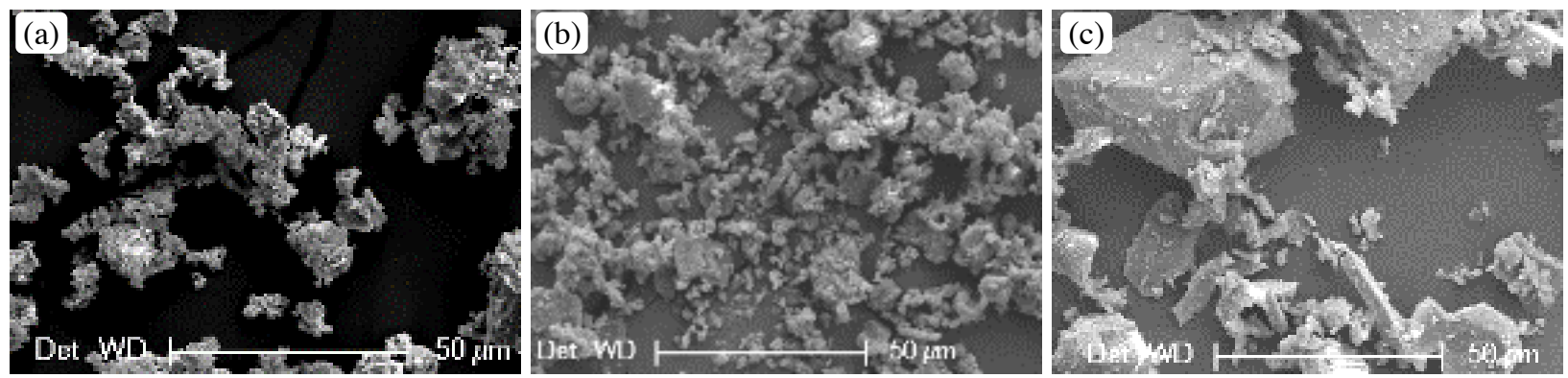

Şekil 3. Hammaddelerin SEM görüntüleri: (a) Çimento, (b) Mermer Atı̆̆ı, (c) Silis Kumu (Ölçek 50 ㅆm: 500x büyütme)

\section{Üretilen Fiber-Sement Kompozit Malzemelerin Özellikleri}

Mermer atı̆̆ı katılmış ve katılmamış olarak üretilen Fiber-Sement kompozit malzeme örneklerinin fotoğraf makinası ile çekilmiş resimleri sırasıyla Şekil 4 'de görülmektedir. Ürünler aynı koşullarda üretilmiş olmasına rağmen A2 ve A3 numunelerinin boyutlarının daha küçük olduğu fiber matris arasındaki ara yüzeyde daha mükemmel bir bağlanmanın oluştuğu ve dolayısıyla buna bağlı olarak diğer fiziksel özelliklerinde de önemli bir farkl1lığın oluştuğu gözlemlenmiştir. Bütün ürünlere ait Yük-Deplasman diyagramı ve Gerilme - Gerinme grafiği Şekil 5'de sırasıyla gösterilmiştir. Sonuçlara göre A2 ve A3 numunelerinin mekanik testlerinde aynı karakteristik davranışı sergileyen diğer ürünlere göre yüksek mukavemet değerlerine sahip olması dikkat çekmektedir. Numunelerde "Birim Deformasyon Sünekliğil" araştırılmıştır. Şekil 5 ve 6 incelendiğinde A0, A1 ve A2 numunelerinin düşük süneklik ve A3, A4 ve A5 numunelerinin yüksek süneklik davranış1 sergilediği görülmektedir. Ancak, A2 ve A3 kendi aralarında davranış açısından farklılık sergilemektedir. A3 daha sünek bir karakteristik sergilerken A2'nin mukavemet değeri daha yüksek olmakla birlikte daha az sünek davranış sergilemektedir. Dolayısıyla, yapıya katılan atık mermer tozu oranını değiştirerek farklı kullanım alanları için farklı mukavemet özelliklerine sahip farklı FS kompozit malzemelerin üretimi mümkün olabilmektedir.
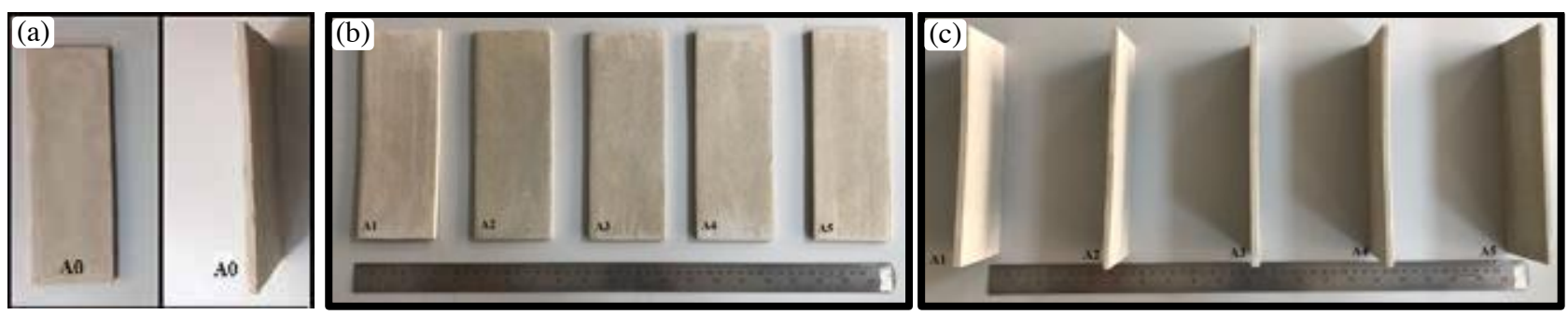

Şekil 4. Mermer atığı kullanılmamış ürün (a), mermer atık oranı \%10-50 arasında olan nihai ürünlerin yatay şekilleri (b) ve dikey şekilleri (c)
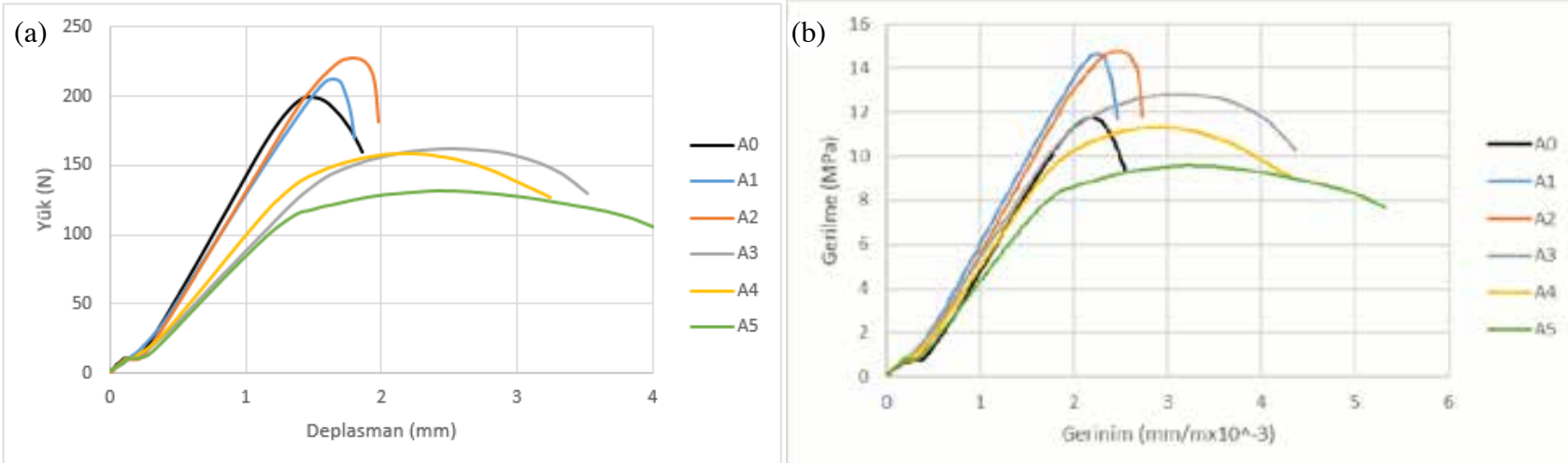

Şekil 5. Üretilen numunelerin Yük-Deplasman eğrisi (a), Gerilme-Gerinme Grafiği (b) 
Üretilen numunelerin mekanik mukavemet sonuçları, Kırılma Mukavemeti değerleri $\mathrm{MPa}$; Elastikiyet Modülü değerleri ise GPa birimlerinde ölçülerek Çizelge 4'de gösterilmiştir. Şekil 6, Kırılma Mukavemeti (a) ve Elastik Modülü (b) değerlerinin grafiksel gösterimidir. Tüm FS numuneleri aynı koşullar altında pişirilmesine rağmen, farklı mekanik özellik göstermelerinin nedenleri doğrudan mermer atığ1 miktarı ve özellikleri ile bağlantılı olmasıdır. Numunelerin kütle yoğunluğu ve su emme sonuçları da Çizelge 5'de gösterilmiştir.

Çizelge 4. Üretilmiş olan Fiber-Sement'lerin mekanik mukavemet sonuçları

\begin{tabular}{lcccccc}
\hline & A0 & A1 & A2 & A3 & A4 & A5 \\
\hline $\begin{array}{l}\text { Kırılma Mukavemeti } \\
\text { (MPa) }\end{array}$ & 11.75 & 14.65 & 14.76 & 12.82 & 11.31 & 9.58 \\
Elastik Modülü (GPa) & 7.16 & 7.69 & 7.55 & 6.47 & 6.32 & 5.56 \\
\hline
\end{tabular}
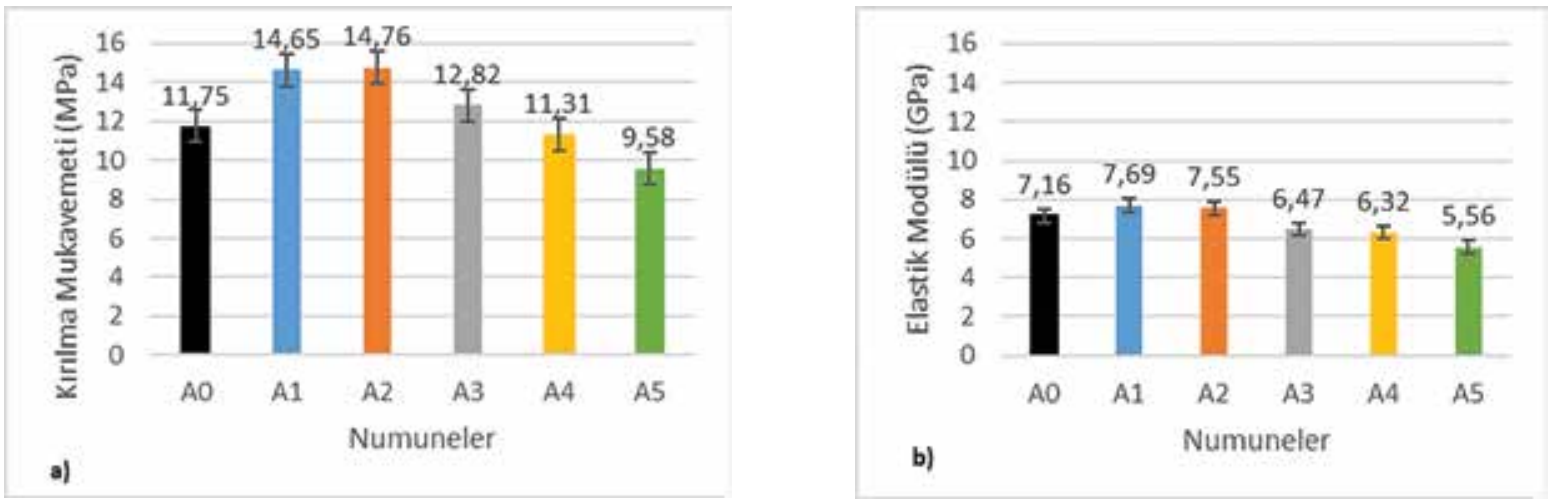

Şekil 6. Üretilen numunelerin (a) Kırılma Mukavemeti ve (b) Elastik Modülü değerlerinin grafiksel gösterimi

Çizelge 5. Kütle yoğunluğu ve su emme değerleri

\begin{tabular}{lllllll}
\hline & A0 & A1 & A2 & A3 & A4 & A5 \\
\hline Kütle yoğunluğu $\left(\right.$ g.cm $\left.^{-3}\right)$ & 1.39 & 1.43 & 1.44 & 1.47 & 1.53 & 1.51 \\
Su emme (\%) & 26.6 & 20.9 & 20.9 & 22.7 & 19.8 & 21.8 \\
\hline
\end{tabular}

Yapılan testlere göre en yüksek yoğunluğa sahip ürünler A4 ve A5 ve su emme oranı en düşük ürünler A4, A1 ve A2'dir. A4 ve A5'in yoğunluklarının yüksek olmasının en önemli sebebinin yüksek mermer atığ katkısı olduğu düşünülmektedir. Ancak, fiber matris ara yüzey ilişkisi göz ard1 edilmemelidir. Dikkat çekici durum; A5 numunesinin yoğunluğunun yüksek olmasına rağmen su emme oranının da (\%21.8) üçüncü sırada yüksek olmasıdır. Ürünün su emme oranının yüksek olması mikroyapıdaki su difüzyonuna izin veren gözeneklerin fazla olmasından kaynaklanmaktadır. En dikkat çeken önemli sonuç A2 ve A3 numunelerine aittir. A3, ortalama bir yoğunluğa sahip olmasına rağmen su emme oranı en fazla olan ikinci üründür. A3'ün dikkat çekici olması sünek deformasyon davranışı sergileyen ürünler içerisinde en yüksek mukavemete sahip olmasıdır. Dolayısıyla, elastik deformasyon davranışı yüksek olması istenen bir kompozit malzeme için A3 numaralı ürün beklentilere cevap verebilecek özelliklere sahiptir. Ancak, yapısı nedeniyle daha az su emme özelliği olan, daha yüksek mukavemet ve daha az sünek davranış sergileyen A2 numaralı ürün kompozit malzeme karakteristiği açısından daha üstün özelliklere sahiptir. Şekil 7'deki bu ürünlere ait SEM mikro yapıları incelendiğinde A2 numaralı ürünün yaprak şeklinde ve rastgele yönlenmiş çok küçük boyutlardaki taneciklerden oluştuğu görülmektedir. A2'nin A3'e göre daha az sünek davranış sergilemesi 
ve sünek davranış sergilemeyen diğer ürünlere göre (A0 ve A1) daha yüksek kırılma mukavemeti değerine sahip olması ancak sahip olduğu bu mikroyapı ile açıklanabilir. Şekil 7'de (A2) görüldüğü gibi farklı doğrultularda yönlenmiş yaprak şeklindeki taneciklerin fiberlerin sünek davranışını azalttığı düşünülmektedir. A2'nin su emme özelliğinin en düşük olmasına rağmen yoğunluğunun A4 ve A5'e göre daha düşük olmas1 ancak yapısındaki kapalı gözeneklerle izah edilebilir.
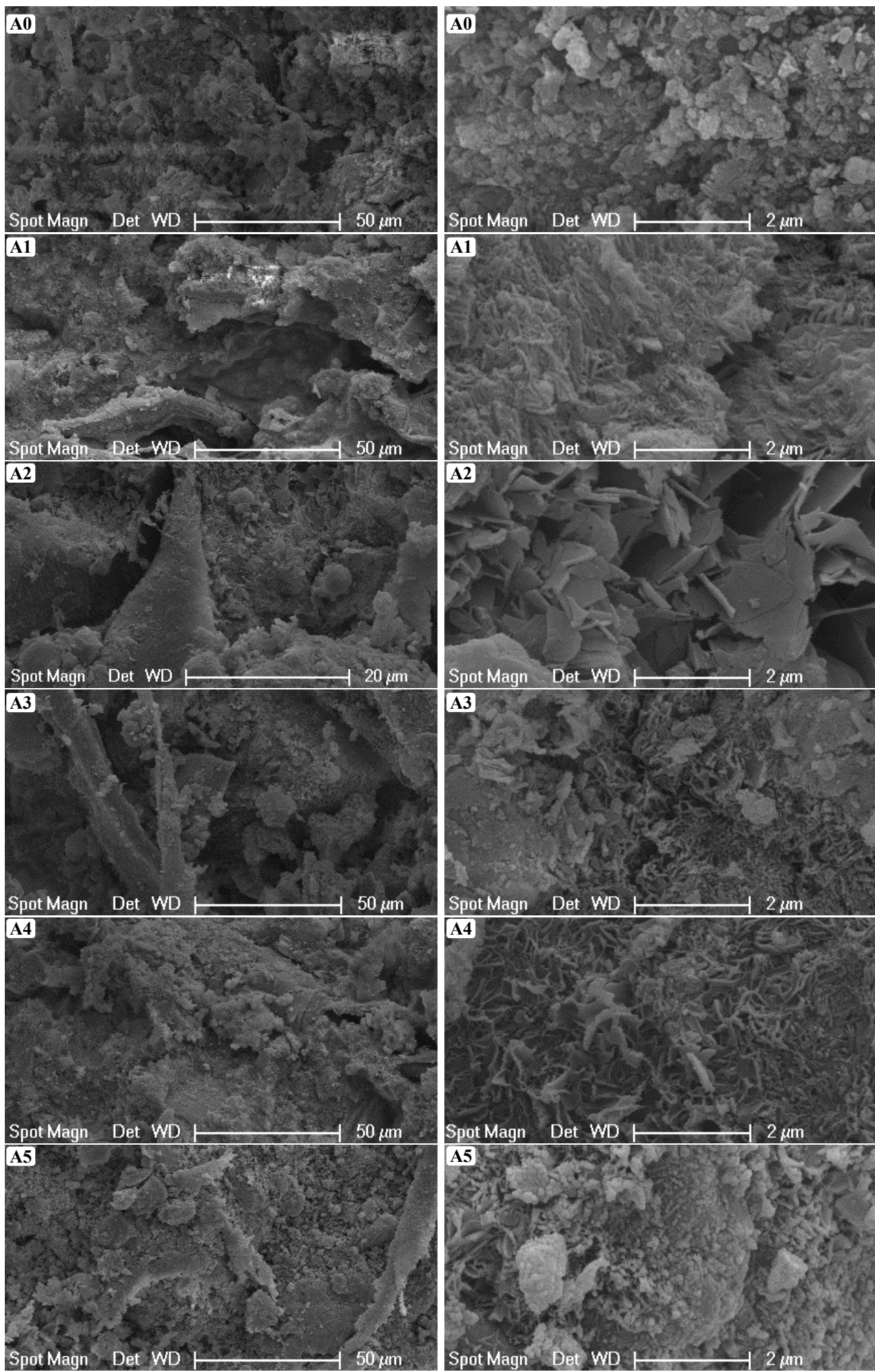

Şekil 7: Üretilmiş Fiber-Sement nihai ürünlerin SEM mikroyapı görüntüleri (Ölçeklerde $2 \mu \mathrm{m}$ : 10000x, $20 \mu \mathrm{m}$ : 1500x ve 50 $\mu \mathrm{m}$ : 500x büyütmedir.). 


\section{SONUÇ}

Üretilen ürünlerin planlanan kalınlık hedefi $8 \mathrm{~mm}$ olmakla birlikte elde edilen sonuçlar $7.75 \mathrm{~mm}$ 'dir. TS EN 12467 standardının 5.3.4.2. maddesine göre \pm 1 mm'lik farklar kabul edilebilir değerlerdir.

Çalışmalar sonucunda FS üretiminde mermer atığ katkısının \%20-30 arası olması durumunda elde edilen ürünlerin mekanik özelliklerine etkisinin maksimum seviyede olduğu anlaşılmıştır. Yapılan çalışmalar neticesinde TS EN 12467 standartlarına uygun nitelikte, atık mermer tozu kullanılması durumunda hem istenilen mukavemet değerlerine sahip hem de

\section{KAYNAKLAR}

Alyamac KE, Ghafari E, Ince R, 2017. Development of eco-efficient self-compacting concrete with waste marble powder using the response surface method. Journal of Cleaner Production, 144, 192-202.

Çetin T, 2003. Türkiye mermer potansiyeli, üretimi ve ihracatı. Gazi Üniversitesi Gazi Eğitim Fakültesi Dergisi, 23 (3), 243-256.

Ceylan H, Mança S, 2013. Mermer parça atıklarının beton agregası olarak değerlendirilmesi. SDU Teknik Bilimler Dergisi, 3 (2), 21-25.

Ceylan H, Saraç S, Özkahraman T, 2001. Mermer toz atıklarının derz dolgu malzemesi (fuga) üretiminde kullanılabilirliğinin araştırılması. Türkiye III. Mermer Sempozyumu (Mersem 2001) Bildiriler Kitab1, 3-5.

Demir İ, Başpınar M, 2003. Mermer tozu atıklarının (havuz çözeltisi) hafif yapı blokları üretiminde kullanılması. Türkiye IV. Mermer Sempozyum (Mersem 2003) Bildiriler Kitab1, 1819.

Filiz M, Özel C, Soykan O, Ekiz Y, 2010. Atık mermer tozunun parke taşlarında kullanılması. Electronic Journal of Construction Technologies/Yap1 Teknolojileri Elektronik Dergisi, 6 (2), 5772.

International Organization for Standardization (ISO), 2001. Determination of drainability part 2: "Canadian standard" freeness method. ISO 5267-2:2001. Standard handbook; paper, board and pulps. International Organization for Standardization, Geneva.

Jarabo R, Fuente E, Monte MC, Savastano Jr H, Mutjé P, Negro C, 2012. Use of cellulose fibers from hemp core in fiber-cement production. Effect on flocculation, retention, drainage and product properties. Industrial Crops and Products, 39, 89-96.

Kacir S, 2017. Bilecik mermer sektörü raporu, Bursa Eskişehir Bilecik Kalkınma Ajansı (BEBKA), Bursa.

Kara C, Yazicioglu S, 2016. Mermer tozu atı̆̆ı ve silis dumanının betonun karbonatlaşma özelliğine etkisi. Journal of Science, 5 (2), 191-202. daha ekonomik ve daha çevreci A kategorisinde 2. Sinıf ve 1. seviye kalitesinde bir FS kompozit malzeme üretimi gerçekleştirilmiştir.

\section{TEŞEKKÜR}

Çalışmalarda yapılan test ve analizlerle ilgili verdikleri değerli destekleri için Gebze Teknik Üniversitesi personeli Sayın Ahmet Nazım ve Adem Şen'e, deneyler esnasındaki yardım ve katkılarından dolayı Vefa Holding'den Uğur Arslan'a ve kıymetli destek ve teşvikleri için Vefa Holding ve Ekobord A.Ş.'ye teşekkür ederiz.

Khorami M, Ganjian E, 2011. Comparing flexural behaviour of fibre-cement composites reinforced bagasse: Wheat and eucalyptus. Construction and Building Materials, 25, 36613667.

Kore SD, Vyas A, 2016. Impact of marble waste as coarse aggregate on properties of lean cement concrete. Case Studies in Construction Materials, 4, 85-92.

Rashid RA, Shamsudin R, Hamid MAA, Jalar A, 2014. Low temperature production of wollastonite from limestone and silica sand through solid-state reaction. Journal of Asian Ceramic Societies, 2, 77-81.

Singh M, Srivastava A, Bhunia D, 2017. An investigation on effect of partial replacement of cement by waste marble slurry. Construction and Building Materials, 134, 471-488.

Singh R, Bhutani M, Syal T, 2015. Strength evaluation of concrete using marble powder and waste crushed tile aggregates. International Journal for Science and Emerging Technologies with Latest Trends, 20, 18-28.

Sutcu M, Alptekin H, Erdogmus E, Er Y, Gencel O, 2015. Characteristics of fired clay bricks with waste marble powder addition as building materials. Construction and Building Materials, 82, 1-8.

Talah A, Kharchi F, Chaid R, 2015. Influence of marble powder on high performance concrete behavior. Procedia Engineering, 114, 685-690.

TAPPI, 1999. T. 227 om-94-Freeness of pulp (Canadian standard method). TAPPI Testing Methods, TAPPI Press.

TS EN 12467, ICS 91.100.40, 2007. Düz levhalar - elyaf takviyeli çimento kullanılarak imal edilmiş - mamul özellikleri ve deney metotları.

Ünal O, Kibici Y, 2001. Mermer tozu atıklarının beton üretiminde kullanılmasının araştırılması. Türkiye III. Mermer Sempozyumu, Afyon, Türkiye, Bildiriler Kitab1, 317-325.

Yıldız Ö, Eskikaya Ş, 1995. Afyon mermerleri toz artıklarının değerlendirilmesi. Türkiye I. Mermer Sempozyumu Kitab1, 45-52. 